\title{
Editorial
}

\section{Upping the Stakes}

\section{WENDY HARCOURT}

The last three issues of Development have focused on the political concerns underlying the Millennium Development Goals (MDGs), the movement of movements and peacebuilding. This final issue of volume 48 tackles an equally contentious political subject - sexual and reproductive health and rights (SRHR).

The SRHR agenda covers vast ground. It refers to women's rights to public health systems that provide good quality pre- and postnatal care; affordable and available family planning; access to emergency obstetric services; the need for girls and boys' sex education; men's responsibilities to prevent unwanted pregnancies; the feminization of HIV/ AIDS; violence against women; and gender equality practices in the home and community. SRHR brings many tabooed 'private' subjects into the public sphere. It differs from other development discourses, including those on health and culture, by directly dealing with the fundamental gendered relations of the reproductive body, desire and sexuality. It translates intimate, highly culturally specific behaviours into medical, technical and legal terms within the discourse of rights and development.

Our individual or culturally dictated choices of sexual and reproductive behaviour determine our health, our livelihoods, our domestic situation as well as our cultural and social identity. Complex legal systems are put in place to govern reproductive behaviour, informed by religious, cultural and economic concerns. Women, men and children's rights to health and protection as sexual and reproductive subjects are also determined by shifts in finance and trade and patterns of distribution of economic growth. Sexuality and reproductive behaviour are at the centre of enormously powerful economies. There are profuse and powerful global markets built on the trade in sexualized bodies (largely women and children's) evidenced in pornography, sex work, the entertainment industry and trafficking. Sexuality and reproductive behaviours are used in advertising of all sorts and they drive profitable pharmaceuticals, health and medical industries.

Pleasure and reproductive behaviour and their consequences are a potent mix in all our lives. It is important to recognize the courage of the development community to take on this complex agenda in the 1990s. Pushed by the women's movements around the world, the International Conference on Population and Development Programme of 
Action agreed to in Cairo September 1994 was something of a pinnacle in putting SRHR on the development agenda. It was, some might argue now, an extraordinary moment of consensus among population and environment activists, demographers, women's movements and medical and public health experts and development bureaucrats. Development traced that growing consensus and 'paradigm' shift from population control to women's rights in several journal issues. ${ }^{1}$ Now, eleven years later, despite attempts to put the Cairo promises into action, we are seeing cracks in the consensus and deliberate attempts to squash an open democratic debate on the deeper implications of the sexual and reproductive rights and health agenda.

Today's discussions are marked by quite different conversations, reflecting the neo-conservative climate of the early twenty-first century dominated by the dogma of the free market, the United States led war on terror and a fragile UN. Globally, there is increased poverty and inequities, and a growing public acceptance of 'the world order' as media and savvy politicians play on our fears. Simultaneously, advertising plays on our desires to escape and forget our real lives, the run down health and failing education systems and destabilized environment and escalating wars. Sadly, too many working on SRHR are backsliding in the face of powerful opposition. At best they aim to hold ground. They couch their programmes in words that do not 'upset' the donors. In so doing they do not serve the needs of the 1.2 billion living in poverty; the millions without access to water; education and good public health services; the thousands of women raped and killed in today's wars; and the mothers who die every minute in child birth. In reaction to conservatism and religious fundamentalism, particularly that of US Christian conservatives, open discussions about issues such as abortion are being silenced. Such politically expedient silence contributes to the backlash against women's rights to choose a healthy and autonomous life and their rights to sexual expression and pleasure. It fails to keep the pressure on governments to deliver the many promises of the 1990s, as well as consolidating
The stakes are even higher now for development and women and health activists to fight against the strong neo-liberal and neo-conservative agendas and the fearful images of the mainstream media. We urgently need to keep sexual health and rights at the core of progressive, socially just human development.

Development goes to press at the conclusion of the UN World Summit and in the aftermath of Hurricane Katrina. The reports in the mainstream and alternative press as well as key civil society websites indicate disturbing trends for the fulfillment of the SRHR agenda. At the UN Department for Public Information DPI-NGO Conference held the week before, the launch of the excellent UNDP International Human Development Report 2005 on 'International Cooperation at a Crossroads: aid, trade and security in an unequal world' (http://www.undp.org) warned that rich countries had to hold their own in the global partnership bargain. While praising civil society campaigns (for example The Global Call Against Poverty) that have pushed governments to tackle debt and make more funds available, in particular for Africa, the HDR painted a depressing picture of the deep inequalities that divide humanity and underlined the need to forge a new, more just pattern of globalization.

The World Summit was to be the moment to strike the new pathway for development, building on the Secretary General's 2005 'In larger freedom: towards development, security and human rights for all' (http://www.un.org/largerfreedom/). Over 170 world leaders assembled at the UN General Assembly in New York to tackle aid, debt, trade, peace and security and human rights as well as UN reform. It is perhaps significant that on the opening day newspapers around the world carried the story not of world governments making a grand bargain to live up to promises made to the world's poor but of a sheepish US President asking his Secretary of State whether he could hold up proceedings in order to go to the bathroom.

With John Bolton appointed US Ambassador to the UN weeks before the Summit, the washed out result was more or less predictable. Exhaustive negotiations were held to remove the 750 amendments imposed by the US on the draft text in time for 
the Summit opening. It was with considerable relief inside and outside the UN that there was a document at all.

At least the MDGs were reaffirmed, despite Bolton's earlier attempts to derail them completely. There was undoubted success in reaffirming commitments to gender equality. The vigilance of the women activists at the UN and earlier in the Millennium Project led to women's rights emerging as a key set of agreements in the final Summit document. MDG 3 on Gender Equality was extended to include: an end to impunity for violence against women; the goal of universal access to reproductive health; the right to own and inherit property; equal access to labour protection; and increased representation of women in government decision-making bodies. World leaders agreed to repeal all laws that discriminate against women and promised to implement the Security Council resolution 1325 which promotes women's increased participation in peace and security processes.

Nevertheless, governments failed to explain not why progress to meet the goals had happened, nor why the first target of universal primary education for girls had not been met. No collective agreement was made with clear timetables to meet the ODA target of 0.7 per cent (a promise made 40 years ago). Instead, a vague agreement for half that amount was promised for 2010. Universal debt cancellation was replaced by the weaker G8 proposal for partial debt cancellation for only 18 out of 62 countries stricken by debt burdens. Worryingly, flows freed from debt reduction could well be considered by some countries to be part of their promised aid. Nothing was said about rich countries responsibilities, nor about fresh flows of money to enable developing countries to invest in key social sectors. The subject of external conditionalities imposed by the Bretton Woods Institutions and WTO was left untouched. Instead of an honest debate around changing the trade regime to stop forcing poor countries to open their markets at any cost, and ensure that rich countries act fairly to open theirs, the final statement and a slew of rich nation leaders' statements pushed trade liberalization as the only option for poor countries to end poverty (see http://www.actionaid.org).

It was a disconcerting time for the many civil society members watching the proceedings (outside the UN building). As predicted the security and anti-terrorism agendas were strongly backed, along with responsibility to protect and a new peace building commission. Equally predictable, given the US administration behaviour around Hurricane Katrina, the agreement on climate change took a step back from the already weak agreement made during the G8 at Gleneagles.

In short, there was neither political will to tackle poverty nor any serious commitment to trade reform, debt relief and financial resources for development, all with serious implications for the SRHR agenda. With no change to trade, economic and financial agreements, with no pressure on rich governments to hold to their half of the bargain, there will be no resources to create the enabling environment needed for SRHR. As Virginia Vargas in her statement on behalf of civil society eloquently put it:

A life free of want will be possible only if we recognize the fundamental role of women in the productive and reproductive economies... Where are the new instruments of accountability and global taxation for the multinational corporations? Where are the international norms to control their expropriation of the cultural and natural wealth of peoples by global capital? How long must fatal pandemics, such as HIV/AIDS, be subordinated to the profit-making interests of transnational corporations? How long before scientific progress is put in the service of humanity instead of being monopolized by the market? ... What kind of liberty can be enjoyed without the recognition of sexual rights and reproductive rights and the right to different forms of sexuality and love? ... A life without fear for millions of women requires consideration of violence as a brutal violation of human rights, in all its spheres-domestic, sexual and in armed conflicts...' (Vargas, 2005).

Attending some of the Summit preparations in New York, ${ }^{2}$ I can report that UN debates were not making the local headlines. Instead the news was full of the plight of the poor, mostly women and children of colour, stranded by Hurricane Katrina and the failure of the most powerful nation on Earth to deal with the disaster. The impact of 


\section{Development 48(4): Upfront}

Katrina was strongly present also in the UN. Opening the 58th Annual DPI/NGO meeting activist Wahu Kaara from Kenya and the Africa Social Forum had a standing ovation for her comments on poverty and lack of government accountability in the US. (see http://www.undpi.org) In the corridors a senior African diplomat told me, with a hint of glee: how can the US continue to claim power and world leadership when it cannot deal with its own poverty and natural disasters. And the US women activists whom I visited were close to tears at a report on Louisian that they had just heard on the radio telling me frankly that we have to deal with our own poverty, racial discrimination and gender inequality as much as the world's.

One of them later sent me an article by Zillah Einstein on Hurricane Katrina that brought home how gender and poverty are so intimately linked in that disaster. Speaking of the poor women of colour in Louisiana and Mississippi who bear the brunt of the storm and its aftermath she mirrors Virginia Vargas and many of the authors in this journal issue when arguing that gender and sexual and reproductive health and rights have to be at the core of a political agenda to end poverty:

'The gendering of the storm and its effects do not make headlines. But they should because poverty is tied to family structures in crisis. Poverty is tied to the unavailability of contraceptives and reproductive rights. Poverty is tied to teenage pregnancy. Poverty is tied to women's wages that are always statistically lower than men's. Poverty is tied to the lack of day care for women who must work. Poverty is tied to the lack of access to job training and education' (Einstein, 2005).

We need to expand the democratic space to ensure that the rights and needs of poor women wherever they live in the world are not thrown away, derailed, made invisible or forgotten. It is only by fully including all that a SRHR agenda demands that we will have a fully democratized and economically and racially just society for all men and women and children. The stakes are indeed high, and we cannot afford to wait for yet another lack lustre UN World Summit to 'build a different world, without poverty and exclusions' (Vargas, 2005).

\section{Notes}

1 From 1993 to 2003 Development devoted eleven editions of the journal to articles debating the UN discourses around migration, HIV/AIDS, population, gender, reproductive rights and health.

2 The launch of Development 48.3 'Peace building through justice' was held at one of the midday workshops see www.sidint.org/development for a short report.

\section{References}

Einstein, Zillah (2005) 'Katrina and her gendering of race and class', 12 September WHRnet (hosted by AWID): http://whrnet.org/docs/issue-katrina.html.

Vargas, Virginia (2005) A United Nations Truly for We the Peoples Civil Society Presentation to the World summit' 16 September Centro de la Mujer Peruana Flora Tristan; Articulación Feminista Marcosur; International Council of the World Social Forum; Feminist Task Force of the Global Call to Action against Poverty (GCAP) http://www.whiteband.org/. 